\title{
О СОСТАВЕ САПРОПЕЛЕВЫХ ОТЛОЖЕНИИ ГЛЯЦИАЛЬНЫХ ОЗЕР ЭСТОНИИ
}

Непрерывный процесс накопления осадков в озерных котловинах Эстонии привел к их значительному заболачиванию. Состав озерных отложений весьма разнообразен. Их нижние слои, непосредственно залегающие на гляцигенных отложениях, представлены кластическими и глинистыми отложениями позднеплейстоценового возраста (Пиррус, Раукас, 1969). Для верхних же слоев характерны разные органогенные и хемогенные осадки, в том числе и сапропели, голоценового возраста. Из этих типов отложений основное внимание в настоящей статье уделяется сапропелям. Они содержат многие важные для питания животных аминокислоты, витамины, микроэлементы и другие вещества, а изучены с этой точки зрения довольно слабо (Вебер, 1964; Veber, 1963, 1964, 1970, 1973).

Мощность сапропелевых отложений в изученных озерах колеблется от нескольких десятков сантиметров до $10 \mathrm{~m}$, обычно в пределах $2-3 \mathrm{M}$. Цвет сапропелей меняется в зависимости от состава. Местами они имеют темно-серые или черные тона под влиянием, видимо, железа (оз. Пяйдре). Фито- и зоопланктон придают им зеленоватый оттенок (оз. Кирикумяэ), терригенный материал - серый (оз. Юлемисте и Пангоди). Во многих разрезах встречаются отдельные уровни, обогащенные озерной известью, которая обусловливает серый или бежевый цвет отложений.

Ниже обобщаются аналитические данные по основным свойствам сапропелевых отложений из шести гляциальных озер, расположенных в разных физико-географических районах Эстонии (рис. 1).

3 ол н о с т ь сапропелей колеблется в пределах 5$89 \%$ в пересчете на сухую массу, а обычно составляет $40-50 \%$. Принято различать три типа сапропелей (Бракш, 1971): 1) малозольные $(A c$ до $35 \%), 2)$ среднезольные $(A c \quad 35-50 \%)$ и 3) с повышенной минерализацией $(A c$ более $50 \%)$.

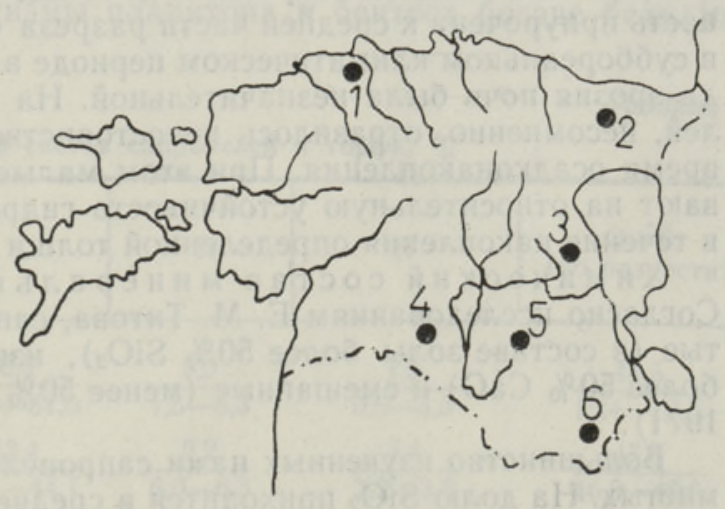

Рис. 1. Схема расположения изученных озер: 1 - Юлемисте, 2 - Ряэтсма, 3 - Элиствере, 4 - Пяйдре, 5 - Пангоди, 6 - Кирикумяэ. 


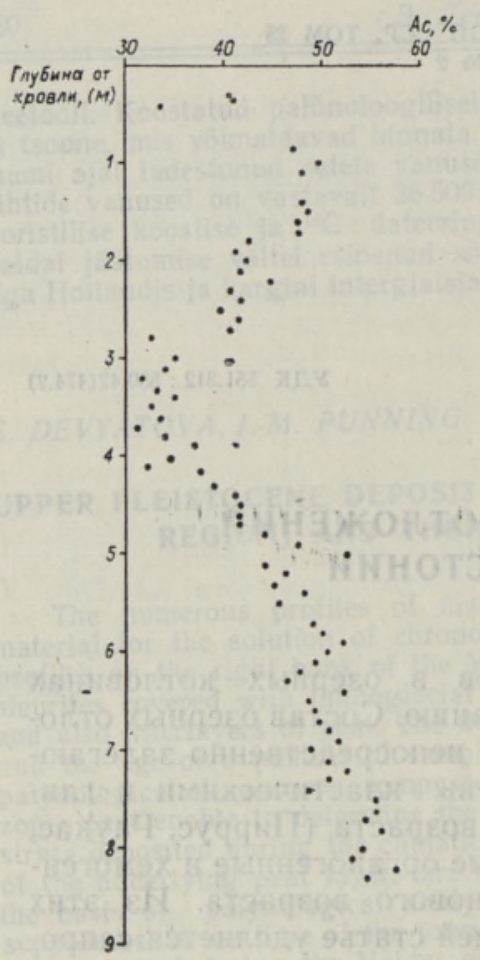

Таблица 1

Химический состав золы сапропелей

(25 определений)

\begin{tabular}{l|r|r|r}
\hline & $\begin{array}{c}\text { Сред- } \\
\text { нее }\end{array}$ & $\begin{array}{r}\text { Минн- } \\
\text { мальное }\end{array}$ & $\begin{array}{r}\text { Макси- } \\
\text { мальное }\end{array}$ \\
\hline 3ольность & 45,0 & 4,9 & 89,3 \\
$\mathrm{SiO}_{2}$ & 60,0 & 43,4 & 91,3 \\
$\mathrm{Al}_{2} \mathrm{O}_{3}$ & 9,5 & 2,6 & 21,5 \\
$\mathrm{TiO}_{2}$ & 0,4 & 0,1 & 1,5 \\
$\mathrm{Fe}_{2} \mathrm{O}_{3}$ & 7,7 & 1,7 & 23,2 \\
$\mathrm{CaO}$ & 12,2 & 1,6 & 31,3 \\
$\mathrm{MgO}$ & 2,1 & 0,2 & 5,5 \\
$\mathrm{P}_{2} \mathrm{O}_{5}$ & 0,7 & 0,1 & 2,4 \\
$\mathrm{~K}_{2} \mathrm{O}$ & 1,8 & 0,4 & 3,5 \\
$\mathrm{Na}_{2} \mathrm{O}$ & 0,4 & 0,1 & 0,8 \\
$\mathrm{SO}_{3}^{\prime}$ & 3,8 & 0,9 & 6,4 \\
& & & \\
& & & \\
\end{tabular}

Рис. 2. Диаграмма зольности отложений оз. Пангоди (вертикальный разрез).

Первые встречаются в изученных озерах редко; они обнаружены нами только в заросшей части оз. Кирикумяэ $(A c-5-13 \%)$, вторые присутствуют в оз. Элиствере, Пяйдре, Пангоди и Ряэтсма и третьи лишь в некоторых частях оз. Юлемисте. Повышенная зольность этого водоема обусловлена, видимо, тем, что источником его питания служат богатые кальцием грунтовые воды.

Распределение зольности по вертикальному разрезу весьма изменчиво даже в пределах одного разреза. Как правило, вверх по разрезу она уменьшается (оз. Кирикумяэ, Пангоди), хотя в разрезе оз. Юлемисте наблюдается обратная картина - повышение зольности от нижних слоев к верхним. В мощной сапропелевой толще оз. Пангоди наименьшая зольность приурочена к средней части разреза (рис. 2), которая образовалась в суббореальном климатическом периоде в условиях сухого климата, когда эрозия почв была незначительной. На изменении зольности сапропелей, несомненно, отразилось непостоянство климатических условий во время осадконакопления. При этом малые колебания зольности указывают на относительную устойчивость гидрологического режима водоема в течение накопления определенной толщи сапропеля.

Хи мический состав минеральной части сапропелей. Согласно исследованиям Е. М. Титова, сапропели бывают: кремнеземистые (в составе золы более $50 \% \mathrm{SiO}_{2}$ ), известковистые (в составе золы более $50 \% \mathrm{CaO}$ ) и смешанные (менее $50 \%$ как $\mathrm{SiO}_{2}$, так и СаO) (Бракш, 1971).

Большинство изученных нами сапропелей относится к типу кремнеземистых. На долю $\mathrm{SiO}_{2}$ приходится в среднем до $60 \%$ от содержания всех химических компонентов (табл. 1). Особенно много $\mathrm{SiO}_{2}$ содержат песчанистые и алевритовые сапропели в нижних частях разрезов оз. Элиствере, Юлемисте и Кирикумяэ. 


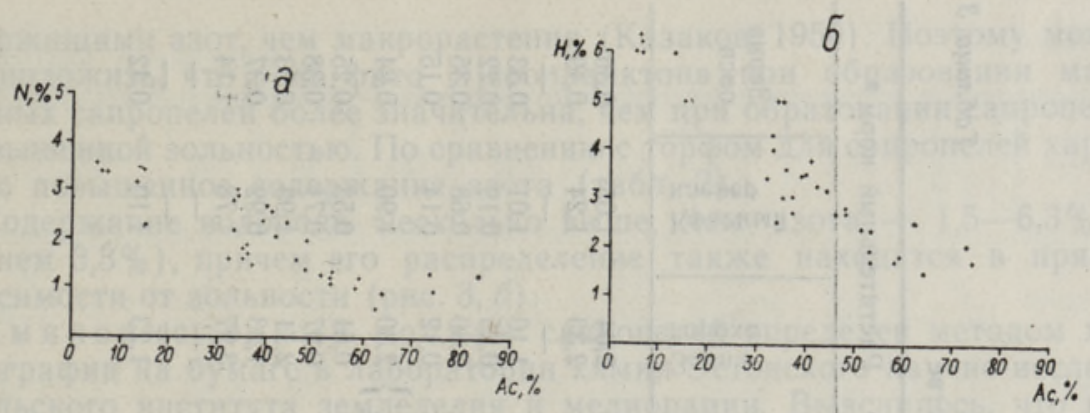

Рис. 3. Зависимость элементарного состава от зольности отложений: а) зольность и содержание азота, б) зольность и содержание водорода.

$\mathrm{CaO}$ в золе сапропелевых отложений сравнительно немного (в среднем $12,2 \%$ ), хотя его количество сильно варьирует в зависимости от характера отложений (табл. 1). Наиболее обогащена кальцием (свыше $20 \%$ ) зола сапропелей оз. Юлемисте и Пангоди.

$\mathrm{MgO}$ содержится в шесть раз меньше, чем $\mathrm{CaO}$ (в среднем 2,1\%). Наибольшие концентрации магния (свыше $3 \%$ ) найдены в золе отложений оз. Пангоди и Кирикумяэ.

Сравнительно большую долю составляют полуторные окиси алюминия (в среднем 9,5\%) и железа (в среднем 7,7\%). Предельно высокое содержание $\mathrm{Fe}_{2} \mathrm{O}_{3}$ в золе оз. Пяйдре обусловлено питанием озера подземными водами из среднедевонских пород, богатых соединениями железа.

Содержание окиси калия $(1,8 \%)$ и фосфора $(0,7 \%)$ в золе сапропелей больше, чем в торфе. При этом фосфор преобладает в малозольных сапропелях (оз. Кирикумяэ). К такому же выводу пришел А. Линдпере (1974), изучавший химический состав поверхностного слоя малозольного сапропеля озер Вийтна $\left(\mathrm{P}_{2} \mathrm{O}_{5}\right.$ в золе $\left.1,1-3,4 \%\right)$.

По данным элем ен тарного соста в а, определенного в лаборатории сектора инструментального анализа Института химии АН ЭССР, содержание углерода в сапропелях изменяется значительно - от 23 до $81 \%$ (в среднем 46\%). Азот составляет $0,6-3,5 \%$ (в среднем $1,9 \%$ ), причем его количество с увеличением зольности убывает (рис. $3, a$ ).

Микрорастения, зооорганизмы планктона и бентоса богаче белками,

Таблица 2

Элементарный состав сапропелей и торфа, \%

\begin{tabular}{c|c|c|c|c|c}
\hline $\begin{array}{c}\text { Местонахож- } \\
\text { дение }\end{array}$ & $\begin{array}{c}\text { Кол-во } \\
\text { опре- } \\
\text { делений }\end{array}$ & $\mathrm{C}$ & $\mathrm{H}$ & $\mathrm{N}$ & $\begin{array}{c}\mathrm{O}+\mathrm{S} \\
\text { (по разности) }\end{array}$ \\
\hline
\end{tabular}

Сапропели изученных озер (рис. 1)

Сапропели оз. Кирикумяэ

Торф окрестности оз. Кирикумяэ
32

$$
\frac{46,3}{23,4-81,0} \quad \frac{3,3}{1,5-6,3} \quad \frac{1,9}{0,6-3,5} \text {. }
$$

4

4

$$
\begin{array}{cc}
\frac{43,4}{42,1-44,1} & \frac{6,2}{6,0-6,3} \\
\frac{44,2}{44,1-44,5} & \frac{5,4}{5,3-5,7}
\end{array}
$$$$
\frac{3,4}{3,2-3,5}
$$

$$
\begin{gathered}
\frac{48,5}{15,4-72,5} \\
\frac{47,0}{46,3-48,6} \\
\frac{49,6}{47,3-49,7}
\end{gathered}
$$

Пр и меч ание. Здесь и в других таблицах в числителе - среднеарифметическое, в знаменателе - мннимальное и максимальное значения. 


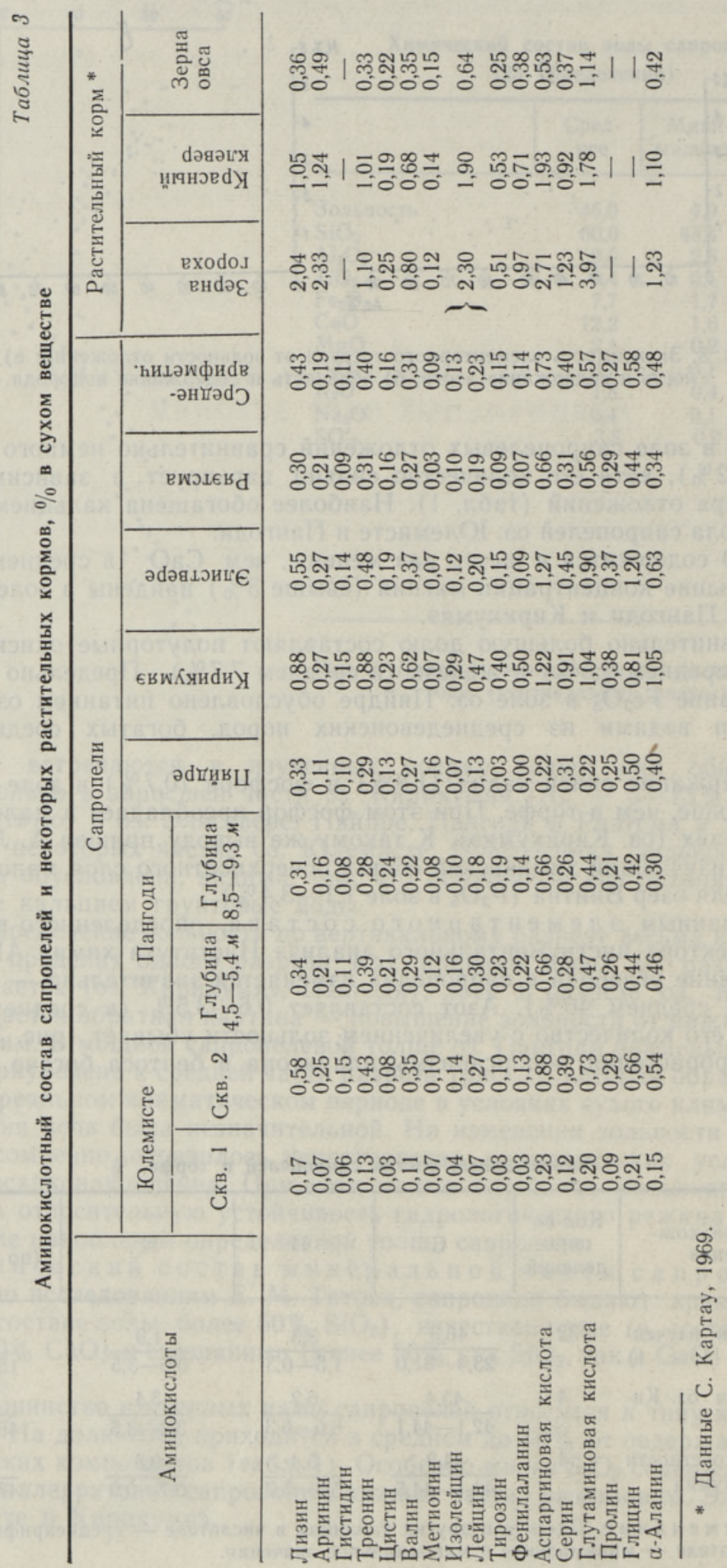


- содержащими азот, чем макрорастения (Казаков, 1950). Поэтому можно предположить, что роль фито- и зоопланктона при образовании малозольных сапропелей более значительна, чем при образовании сапропелей с повышенной зольностью. По сравнению с торфом для сапропелей характерно повышенное содержание азота (табл. 2).

Содержание водорода несколько выше, чем азота - 1,5-6,3\% (в среднем $3,3 \%$ ), причем его распределение также находится в прямой зависимости от зольности (рис. 3, б).

А м и ноки слотны й состав сапропелей определен методом хроматографии на бумаге в лаборатории химии Эстонского научно-исследовательского института земледелия и мелиорации. Выяснилось, что изученные сапропели содержат все основные, необходимые для жизнедеятельности животных аминокислоты (Штрауб, 1963), что особенно важно при использовании их в качестве подкормки скоту (табл. 3). И все же в этом отношении они уступают, за исключением малозольных сапропелей, растительным кормам (табл. 3).

Содержание микроэлементов в золе сапропелей определено спектральным полуколичественным методом в Центральной лаборатории Управления геологии СМ ЭССР. Наиболее распространенными микроэлементами оказались $\mathrm{Ti}, \mathrm{Ba}, \mathrm{Mn}, \mathrm{Zr}, \mathrm{Sr}$ (табл. 4). Их максимальные концентрации связаны, как правило, с кремнеземистыми сапропелями. Известковистые сапропели гораздо ими беднее.

По количественному содержанию первое место занимает титан в среднем 866 г/T, что, однако, почти в пять раз ниже его кларкового содержания в осадочных породах (Виноградов, 1957). Особенно много титана обнаружено в сапропелях оз. Пяйдре. По данным химического анализа, последние богаты и соединениями железа (до 23\%). Это подтверждает вывод Н. И. Семеновича (1973) о совместном накоплении титана, железа и полуторных окислов.

На втором месте стоит барий. Его среднее содержание (308 г/т) примерно в 2,5 раза ниже кларковых значений в осадочных породах $(8002 / T)$, а максимальные количества (в сапропелях оз. Пяйдре) во столько же раз превышают кларковые. Сравнительно высокая концентрация бария в сапропелях связана с хорошей растворимостью и подвижностью этого элемента. В процессе выветривания он переходит в раствор в виде бикарбонатов, хлоритов и сульфатов (Rankama, Sahama, 1955) и имеет тенденцию к совместному накапливанию с железом (Семенович, 1973), чем, очевидно, и объясняется его высокое содержание в сапропелях оз. Пяйдре.

Концентрации марганца достигают в сапропелях оз. Ряэтсма 1560 г/T, хотя среднее его содержание в 2,3 раза ниже кларкового в осадочных породах. В накоплении марганца большую роль играет механический привнос (Страхов и др., 1954).

Медь содержится довольно равномерно во всех изученных сапропелях. Исключение составляет оз. Кирикумяэ, где меди и многих других микроэлементов значительно меньше (табл. 4). Причина кроется, по-видимому, в малозольности сапропелей этого озера и в химическом составе его вод ( $\mathrm{pH}<6,0$; незначительное содержание растворенного кислорода), способствующих подвижности соединений меди и миграции их в растворенном состоянии (Глаголева, 1958; Eesti järved, 1968).

Содержания хрома (в среднем 5,2 г/T), никеля $(52 / T)$ и ванадия $(5,6$ г/T) более чем в восемь раз ниже кларковых, что можно объяснить низкой растворимостью и малой подвижностью этих элементов (Rankama, Sahama, 1955). Повышенные концентрации в сапропелях оз. Пяйд. ре ванадия и хрома, с одной стороны, и окиси железа - с другой, очевидно, взаимосвязаны. 
Содержание микроэлементов

\begin{tabular}{|c|c|c|c|c|c|c|c|c|c|c|c|}
\hline $\begin{array}{l}\text { Место- } \\
\text { нахож- } \\
\text { дение }\end{array}$ & 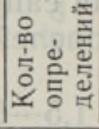 & $\mathrm{Ti}$ & V & $\mathrm{Cr}$ & $\mathrm{Mn}$ & Co & $\mathrm{Ni}$ & $\mathrm{Cu}$ & $\mathrm{Pb}$ & $\mathrm{Zn}$ & $\mathrm{Ga}$ \\
\hline Кирикумяэ & 4 & $\frac{150}{50-185}$ & $\frac{0,3}{0,1-1,0}$ & $\frac{0,4}{0-1}$ & $\frac{14}{5-19}$ & 0 & $\frac{0,8}{0,2-1}$ & $\frac{1,8}{1-3}$ & $<1$ & $\frac{17}{5-38}$ & $<1$ \\
\hline Пангоди & 15 & 945 & 5,4 & 5,7 & 270 & 0,5 & 3 & $\frac{8.5}{2-16}$ & $\frac{2}{0-4}$ & $\frac{1,6}{0-16}$ & $\frac{3}{-10}$ \\
\hline & & 620 & $\begin{array}{r}-16 \\
2,5 \\
\end{array}$ & $\begin{array}{r}1-10 \\
3,8 \\
\end{array}$ & 135 & 1,6 & 5,5 & $\begin{array}{c}2-16 \\
9\end{array}$ & -4 & 12 & 2,1 \\
\hline вер & II & $\overline{190-1770}$ & $0-7$ & $\overline{0-12}$ & $\overline{55-294}$ & $0-4,4$ & $\overline{0-13}$ & $1-13$ & -2 & $\overline{0-36}$ & $0-6$ \\
\hline & & 1440 & 12,4 & 8,9 & 430 & 2,3 & 7 & 14 & 4.4 & 31 & 5,5 \\
\hline Пяй & 21 & $\overline{340-2750}$ & $\overline{3,5-18,0}$ & $1-18$ & $\overline{71-690}$ & $\overline{1,0-3,8}$ & $\overline{4-19}$ & $\overline{3-29}$ & $\overline{0,5-17,8}$ & $\overline{0-114}$ & $2-12$ \\
\hline & & 730 & 5,7 & 1,6 & 530 & 8,1 & 3,8 & 9 & 3,0 & & 5,6 \\
\hline Ряэтсма & & $90-1670$ & $\overline{0,6-23,5}$ & $\overline{0-6}$ & $\overline{190-1560}$ & $\overline{0-59}$ & $\overline{0-18}$ & $\overline{1-35}$ & $\overline{0-11,8}$ & & $1-11$ \\
\hline & tand & 1320 & 7,1 & 8,9 & 370 & 1.9 & 8,6 & 12 & 3,2 & 6 & 4,4 \\
\hline & & $3 \overline{30-3080}$ & $0-15,4$ & $\overline{2-19}$ & $\overline{200-590}$ & $\overline{0-4,6}$ & $\overline{2-33}$ & $\overline{5-33}$ & $\overline{1-7,8}$ & $\overline{0-33}$ & $0,6-11$ \\
\hline
\end{tabular}

Кобальт присутствует в сапропелях в небольшом количестве (в среднем 8 г/T). Высокие концентрации установлены лишь в оз. Ряэтсма до $59 \mathrm{z} / \mathrm{T}$, что явно связано с повышенным содержанием в них марганца, механическая смесь которого с окисью кобальта образует минерал асболан или землистый кобальт (Энерглин, Брили, 1975).

Интересно отметить, что сапропели сравнительно богаты молибденом, особенно сапропели оз. Ряэтсма - 90-50 г/T (в среднем 25 г/T), т. е. эта цифра превышает кларк в осадочных породах в 12 раз. Источником молибдена в районе этого озера являются карбонатные породы ордовика. Этот элемент очень важен с биохимической точки зрения, так как он способствует обмену азота в растениях, а также в значительной мере лимитирует первичную продукцию озер (Goldman, 1960).

Содержание циркония колеблется в больших пределах - от 0 до 716 г/T. Его среднее содержание лишь немного меньше кларкового $(200$ г/T). Низкие концентрации циркония характерны для отложений оз. Кирикумяэ и Элиствере (табл. 4).

Последовательность распределения всех элементов выглядит следующим образом: $\mathrm{Ti}>\mathrm{Ba}>\mathrm{Mn}>\mathrm{Zr}>\mathrm{Sr}>\mathrm{Zn}>\mathrm{Cu}>\mathrm{Y}>\mathrm{V}>\mathrm{Ni}>\mathrm{Cr}>\mathrm{Mo}>$ $>\mathrm{Ga}>\mathrm{Pb}>\mathrm{Co}>\mathrm{Sn}$, что несколько отличается от последовательности кларков в осадочных породах.

В общем содержание всех микроэлементов колеблется в широких пределах, что объясняется особенностями бассейнов сноса. По количественному содержанию они уступают кларковым значениям в осадочных породах. Последнее характерно для всех озерных осадков периферийной части Балтийского щита (Семенович, 1973). Причиной является разбавляющее действие органического вещества.

При сравнении состава сапропелей всех изученных озер выясняется, что малозольные сапропели оз. Кирикумяэ самые перспективные для использования в качестве удобрения полей и подкормки животных, так как они наиболее богаты органическим веществом, азотом и аминовыми кислотами, но бедны микроэлементами. У высокозольных сапропелей картина противоположна. 


\begin{tabular}{|c|c|c|c|c|c|c|c|c|c|c|c|}
\hline $\mathrm{Ge}$ & $\mathrm{Sn}$ & Mo & $\mathrm{Zr}$ & $\mathrm{Y}$ & $\mathrm{Yb}$ & $\mathrm{Be}$ & $\mathrm{Sr}$ & $\mathrm{Ba}$ & B & P & $\mathrm{Sc}$ \\
\hline 0 & 0 & $<1$ & $\frac{30}{20-50}$ & 0 & 0 & 0 & $\frac{10}{0-33}$ & $\frac{30}{10-50}$ & $\frac{3}{0-6}$ & $\frac{73}{0-156}$ & 0 \\
\hline 0 & $<1$ & $\frac{2}{0-8}$ & $\frac{173}{0-455}$ & $<1$ & $\frac{0.1}{0-2}$ & $\frac{0,3}{0-0,5}$ & $\frac{55}{33-95}$ & $\frac{314}{200-500}$ & $\frac{20}{0-52}$ & $\frac{980}{136-5000}$ & $\frac{0,6}{0-3}$ \\
\hline 0 & $<1$ & $\frac{2}{0-7}$ & $\frac{84}{0-294}$ & 0 & 0 & 0 & $\frac{53}{13-180}$ & $\frac{113}{59-270}$ & 13 & $\frac{260}{0-680}$ & 0 \\
\hline 0 & $<1$ & $\frac{4}{0,8-13,8}$ & $\frac{228}{107-455}$ & $\frac{5}{0-14}$ & $<0,1$ & $<0,2$. & $\frac{83}{34-116}$ & $\frac{907}{275-2140}$ & $\frac{20}{0-107}$ & $\frac{193}{0-555}$ & 0 \\
\hline $\begin{array}{c}\text { одной } \\
\text { ipoбе } 4\end{array}$ & $\begin{array}{l}\text { в двух } \\
\text { про- } \\
6 \text { ax } 2\end{array}$ & $\frac{25}{0,5-50}$ & $\frac{207}{0-590}$ & $\begin{array}{l}\text { в двух } \\
\text { про- } \\
6 а 0^{2} 9\end{array}$ & $\begin{array}{l}\text { в трех } \\
\text { пробах } \\
0,6\end{array}$ & $\begin{array}{c}\text { в двух } \\
\text { пробах } \\
1,7\end{array}$ & $\frac{149}{33-833}$ & $\frac{245}{31-666}$ & $\begin{array}{c}\text { в двух } \\
\text { пробах } \\
12,4\end{array}$ & 0 & 0. \\
\hline 0 & $<2$ & $<1$ & $\frac{228}{0-716}$ & $\frac{21}{14-33}$ & $\frac{0,6}{0,3-0,8}$ & $\begin{array}{c}\text { в двух } \\
\text { пробах } \\
0,3\end{array}$ & $\frac{81}{33-230}$ & $\frac{241}{47-830}$ & $\begin{array}{c}\text { В трех } \\
\text { пробах } \\
48\end{array}$ & $\frac{416}{0-1150}$ & $\begin{array}{c}\text { в двух } \\
\text { пробах } \\
2,7\end{array}$ \\
\hline
\end{tabular}

Автор выражает благодарность Л. Сяга, В. Таклая и С. Картау за проведение анализов.

\section{Л И Т Е Р А Т У Р А}

Бр а кш Н. А. 1971. Сапропелевые отложения и пути их использования. Рига.

В е б е р К. Ю. 1964. Сапропелевые месторождения Эстонской ССР. В кн.: Сапропелевые месторождения СССР. М.

В иноградов А. П. 1957. Геохимия редких и рассеянных химических элементов в почвах. M.

Глаголева М. А. 1958. Формы миграции элементов в речных водах. ДАН СССР, 121, № 6 .

Казаков Е. И. 1950. Генезис и химическая природа пресноводных сапропелей. Тр. Ин-та горючих ископаемых. II.

К ар т а у С. 1969. Об изучении аминокислотного состава некоторых кормов Эстонской ССР методом хроматографии на бумаге. Автореф. канд. дис. Тарту.

Л индпере А. 1974. Химический состав поверхностного слоя сапропеля озер Вийтна. Изв. АН ЭССР. Биол., 23, № 4.

Пи р р у с Р. О., Р а у к а с А. В. 1969. О характере и времени освобождения территории Эстонии от ледников последнего оледенения. Вопросы четвертичной геологии. IV. Рига.

Семен ов и ч Н. И. 1973. Донные отложения Онежского озера. Л.

Страхов Н. М. (ред.) 1954. Образование осадков в современных водоемах. М.

Энерглин У., Брили Л. 1975. Аналитическая геохимия. Л.

Ш т р у б $Ф$. Б. 1963 . Биохимия. Будапешт.

Eesti järved. 1968. Tallinn.

Goldman C. R. 1960, Molybden as a factor limiting primary productivity in CastleLake, California. Science, 132, № 3443 .

R a n k a ma K., S a h a m a Th. 1955. Geochemistry. Chicago.

Veber K. 1963. Eesti soodes leiduvatest sapropeelidest. EMMTUI Teaduslike tööde

Veber K. 1964. Sapropeel Eesti järvedes. EMMTUI Teaduslike tööde kogumik, IV. Tallinn.

Veber K. 1970. Mõningate Eesti järvede setted. EMMTUI Teaduslike tööde kogumik, XX. Tallinn.

Veber K. 1973. Põhjasetete geoloogiast ja levikust. Rmt.: Võrtsjärv. Tallinn.

Ннститут геологии

Академии наук Эстонской ССР
Поступила в редакцию 8/XII 1975 
Leili SA.ARSE

\section{EESTI GLATSIAALSETE JÄRVEDE SAPROPEELI KOOSTIS}

Esitatakse kuue Eesti järve (joon. 1) sapropeeli tuhasus, selle vertikaalne jaotus (joon. 2), keemiline koostis (tab. 1), aminohappeline koostis (tab. 3) ja mikroelementidesisaldus (tab. 4). On määratud orgaanilise aine elementaarkoostis (tab. 2) ja selle sõltuvus tuhasusest (joon. $3, a, b$ ).

\section{Leili SAARSE}

\section{THE COMPOSITION OF SAPROPEL FROM ESTONIAN GLACIAL LAKES}

This paper presents the composition of sapropel collected from six Estonian lakes (Fig. 1). The ash content is very varying (Fig. 2). The chemical composition is given in Table 1, the content of carbon, hydrogen and nitrogen - in Table 2 and their dependence on the ash content in Figure $3 a, b$. Quantitative ratios of separate amino acids are varying (Table 3 ). The content of trace elements is mostly lower than in the sedimentary rocks (Table 4). 